\title{
Gallium Phosphide as a material for visible and infrared optics
}

\author{
J. Václavík, D. Vápenka \\ Institute of Plasma Physics ASCR v.v.i., TOPTEC, Sobotecká 1660, 51101 Turnov, Czech Republic
}

\begin{abstract}
Gallium phosphide is interesting material for optical system working in both visible and MWIR or LWIR spectral ranges. Number of a material available for these applications is limited. They are typically salts, fluorides or sulphides and usually exhibit unfavorable properties like brittleness; softness; solubility in water and small chemical resistance. Although GaP has do not offer best optical parameters excels over most other material in mechanical and chemical resistance. The article describes its most important characteristics and outlines some applications where $\mathrm{GaP}$ should prove useful.
\end{abstract}

\section{Introduction}

TOPTEC research centre is working on research project that includes production of optical elements from gallium phosphide and design of infrared and combined visibleinfrared system. As the number of materials applicable in those systems is very limited, GaP important is one a few optical materials that are useable in such designs.

Gallium phosphide crystal is shown in figure 1. It is widely used as a type III-V semiconductor material in LED production. Thanks to $2.26 \mathrm{eV}$ wide bandgap has LED produced solely from GaP emission peak at $555 \mathrm{~nm}$. Emitted light is designated as pure green color, but conversion efficiency is only $0.1 \%$ due to indirect bandgap of a pure GaP. Therefore dopants like nitrogen, zinc or oxygen are used in order to increase LED effifiency. Dopants allow increasing of efficiency more than 100 times, but the efficiency of doped green GaP LED does not exceed $3 \%$.

LEDs with longer central wavelength are produced from material where portion of gallium or phosphorus atoms in crystal's lattice are replaced by different elements. Typical mixed crystal used here is $\operatorname{In}_{\mathrm{X}} \mathrm{Ga}_{(1-\mathrm{X})} \mathrm{As}_{\mathrm{Y}} \mathrm{P}_{(1-\mathrm{Y})}$ or $\mathrm{AlIn}_{\mathrm{X}} \mathrm{Ga}_{(1-\mathrm{X})} \mathrm{P}$ [1]. Such combinations allow good control of bandgap width over wide range, starting from $1.42 \mathrm{eV}$ of GaAs to $2.26 \mathrm{eV}$ of pure GaP. Some o those combined crystals also exhibits direct bandgaps. Properly selected combination is also transparent for emitted wavelength which further leads to an increased extraction efficiency. Most LEDs based on this technology have central wavelength at 565, 585, 605 and $635 \mathrm{~nm}$. Especially interesting are $635 \mathrm{~nm}$ LEDs which have efficiency around $30 \%$ [1].

Gallium phosphide is not just a semiconductor substrate. It is an interesting material for optical application in the same matter as gallium arsenide. Gallium arsenide is mostly used as a semiconductor substrate for high speed electronic and optoelectronic circuits but also as lens material for high power infrared optics where it compete with $\mathrm{ZnS}$ and $\mathrm{ZnSe}$ materials. Typical application of $\mathrm{GaAs}$ lenses is refractive optics for $\mathrm{CO}_{2}$ lasers in cutting and marking machines. Although it is not best material by optical means it wins over other materials by a higher mechanical strength, chemical resistance, thermal conductivity and hardness.

$\mathrm{GaP}$ exhibits the same good mechanical properties as a GaAs but differs in spectral transmission range, which is shifted to shorter wavelengths - from 0.6 to $11 \mu \mathrm{m}$. Such transmission range opens ways to use a $\mathrm{GaP}$ in visible and near infrared application where most of interesting infrared materials is unusable due to absorption. As a number of materials available for building combined VIS-IR optical systems is quite limited, adding another one with different properties allows more freedom in such designs.

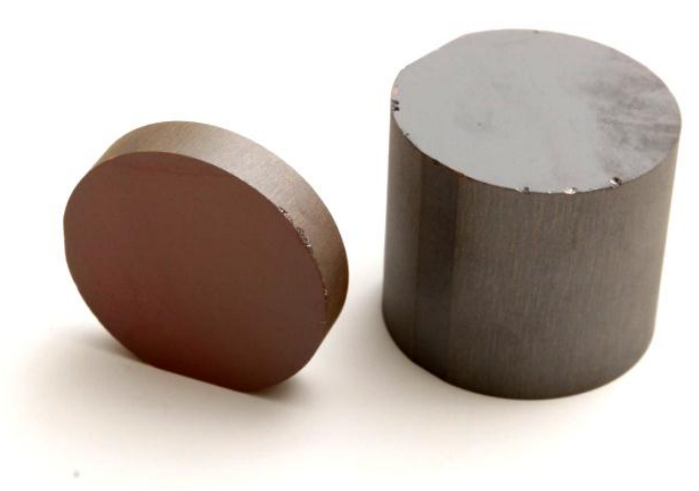

Fig. 1. 2" LEC GaP ingot produced by ITME (Instytut Technologii Materiałów Elektronicznych, Poland) 


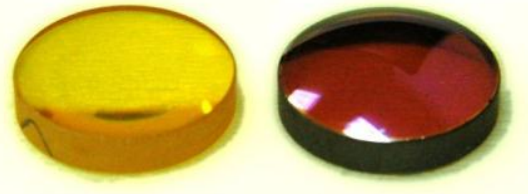

Fig. 2. ZnSe (left) and GaP (rigth) optical elements of bichromatic lenses for VIS and MWIR application

\section{GaP properties}

Evaluating GaP strictly by optical properties will lead into assumption that there are much better materials actually available. Effectively useable spectral range spans from $570 \mathrm{~nm}$ to $11 \mu \mathrm{m}$ which partially limits its use in visible range. There are other materials covering visible to mid infrared range much better - i.e. $\mathrm{ZnS}, \mathrm{CaF}_{2}$ or $\mathrm{BaF}_{2}$. In the infrared end of transmission spectra the $\mathrm{GaP}$ losses to materials like $\mathrm{ZnSe}, \mathrm{BaF}_{2}$ or salts like $\mathrm{KBr}$. Furthermore it exhibits strong dispersion of refractive index in VIS and NIR due to absorption edge at $555 \mathrm{~nm}$. Transmissivity of $\mathrm{GaP}$ and other materials from table 1 is show in figure 3 . What makes $\mathrm{GaP}$ interesting is combination of its main properties [6]

- Transparency from VIS to LWIR

- High refractive index

- High refractive index dispersion in VIS

- Mechanical durability

- Verdet constant: $160 \mathrm{rad} . \mathrm{m}^{-1} \cdot \mathrm{T}^{-1} @ 633$ nm

Some of its important properties are summarized in table 1. Average refractive index of GaP is 3.1. It makes $\mathrm{GaP}$ material with highest value of refractive index for given transparency in VIS range. It lifts up some constrains in design of fast lenses and optical elements, but it is, in the same time, hampered by strong dispersion of refractive index near absorption edge of $\mathrm{GaP}$ as is shown in Fig 4. Therefore favorable applications lie in $800-1000 \mathrm{~nm}$ spectral region which is not part of VIS range but still within sensitivity of Si-based detectors. On the other hand the same dispersion and high refractive index allows design of achromatic pair in combination with $\mathrm{ZnSe}$ element. Production example of such lenses is displayed in figure 2 .

High refractive index requires high quality antireflection coating. So far coatings containing 2 and 4 layers of either $\mathrm{SiO}_{2}-\mathrm{TiO}_{2}$ or $\mathrm{HfO}_{2}-\mathrm{ZnS}$ were realized. Antireflection coating were dual-band having minimum reflectivity at $850 \mathrm{~nm}$ and $4 \mu \mathrm{m}$. Those coatings were used in VIS-MWIR optics for cutting tool diagnostics.

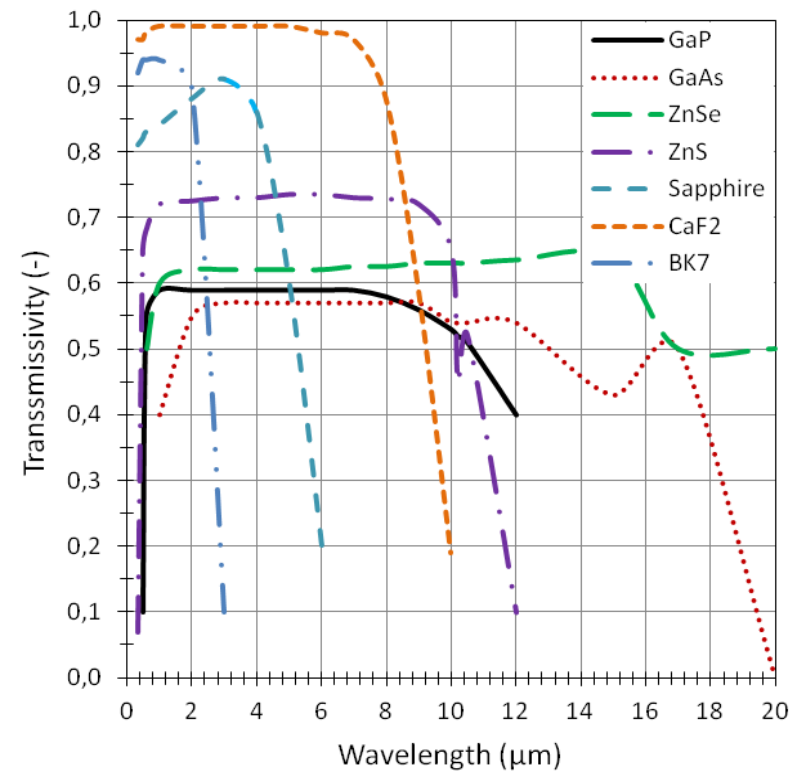

Fig. 3. Transmissivity of different VIS-IR materials in the range $0.3-20 \mu \mathrm{m} .[3,4,8]$

Table 1. Overview of material properties of various optical materials compared to GaP. [3, 4, 6-10]

\begin{tabular}{|c|c|c|c|c|c|c|c|}
\hline & $\mathrm{GaP}$ & GaAs & $\mathrm{ZnSe}$ & $\mathrm{ZnS}$ & Sapphire & $\mathrm{CaF}_{2}$ & BK7 \\
\hline $\begin{array}{l}\text { Refractive Index } \\
\text { at } 1.4 \mu \mathrm{m}\end{array}$ & 3.16 & 3.42 & 2.46 & 2.28 & 1.75 & 1.43 & 1.5 \\
\hline $\begin{array}{l}\text { Transmissibility } \\
\text { at } 50 \%\end{array}$ & $0.6-11$ & $0.9-16$ & $0.55-19$ & $0.45-11$ & $0.22-4.5$ & $0.15-9$ & $0.33-2.3$ \\
\hline $\begin{array}{l}\text { Thermooptical } \\
\text { Coeficient at } \\
\left(10^{-6} \mathrm{~K}^{-1}\right)\end{array}$ & $\begin{array}{c}100 \\
\text { (at } 1.1 \mu \mathrm{m})\end{array}$ & $\begin{array}{c}250 \\
\text { (at } 1.1 \mu \mathrm{m})\end{array}$ & $\begin{array}{c}59-70 \\
\text { (at } 1.1 \mu \mathrm{m})\end{array}$ & $\begin{array}{c}50 \\
\text { (at } 1.1 \mu \mathrm{m})\end{array}$ & $\begin{array}{c}10 \\
\text { (at } 0.6 \mu \mathrm{m})\end{array}$ & $\begin{array}{c}-4 \\
\text { (at } 1.1 \mu \mathrm{m})\end{array}$ & $\begin{array}{c}3 \\
\text { (at } 0.6 \mu \mathrm{m} \text { ) }\end{array}$ \\
\hline $\begin{array}{l}\text { Knoop Hardness } \\
\left(\mathrm{kg} \cdot \mathrm{mm}^{-2}\right)\end{array}$ & 850 & 750 & $105-120$ & $160-220$ & 1700 & 158 & 520 \\
\hline $\begin{array}{l}\text { Flexural Strength } \\
\text { (MPa) }\end{array}$ & 100 & 55 & 50 & 60 & $500-1060$ & 90 & 50 \\
\hline $\begin{array}{l}\text { Fracture } \\
\text { Thoughness } \mathrm{K}_{\mathrm{IC}} \\
\left(\mathrm{MPa} \cdot \mathrm{m}^{1 / 2}\right)\end{array}$ & 0.9 & $\begin{array}{c}0.4 \\
\text { (orientation- } \\
\text { depended) }\end{array}$ & $\begin{array}{c}0.33-0.5 \\
\text { (polycrystali } \\
\text { ne) }\end{array}$ & 0,5 & 3 & 0.5 & $0.82-1.1$ \\
\hline Price $[€ / \mathrm{kg}]$ & 4500 & 2200 & 1800 & 1400 & 3000 & 600 & 70 \\
\hline
\end{tabular}


Mechanical durability is the most important parameter of the GaP material. Materials with similar transmission range are usually brittle, soft and sensitive to thermal shocks [10]. GaP itself is harder than common optical glasses (BK7), fracture toughness the same or higher than of glass and its flexural strength is also significantly higher. It is insoluble in water and has high acid and alkali resistance. $\mathrm{GaP}$ is very durable material compared to commonly used VIS-IR materials like $\mathrm{BaF}_{2}, \mathrm{CaF}_{2}$, $\mathrm{ZnS}, \mathrm{ZnSe}, \mathrm{Kbr}, \mathrm{KCl}$. It is suitable as a material for optical elements exposed to mechanical strain, harsh weather conditions or abrasive dust - i.e. windows, cover domes or front elements of optical systems.

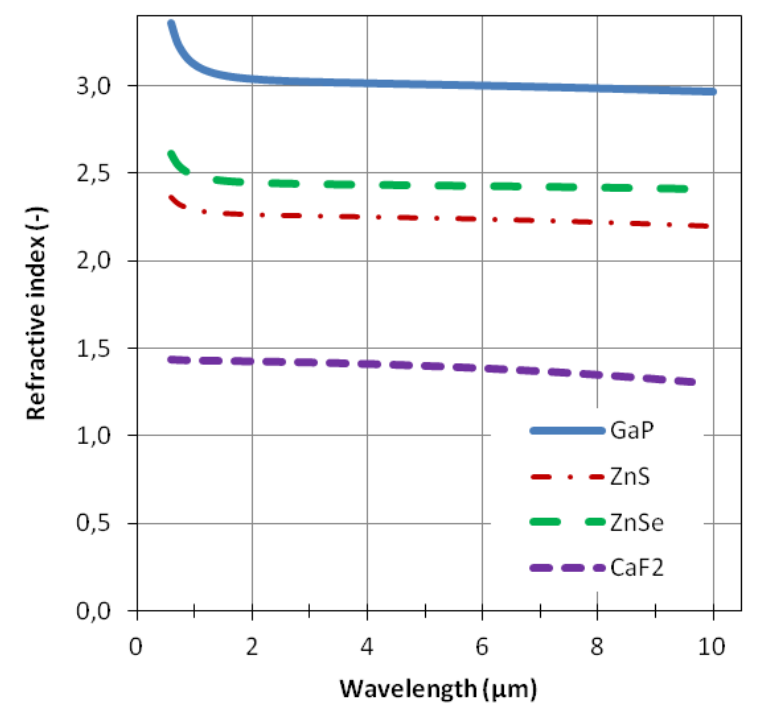

Fig. 4. Refractive indices of various VIS-IR materials as a function of wavelength in range $0,6-10 \mu \mathrm{m}$. $[3,4]$

\section{GaP production}

GaP useable for optical application must be udoped, have minimum of lattice dislocation and minimum free carriers. Free carriers causes bulk absorption of light in the material at longer wavelength. Minimal specifications for GaP optical material are:

- Undoped material

- Carrier concentration: $<10^{16} \mathrm{~cm}^{-3}$

- EPD (Etch Pit Density): $<5.10^{3} \mathrm{~cm}^{-2}$

GaP crystal is grown byt LEC (Liquid Encapsulated Czochralski) method. It is well-proven method used by most semiconductor producers to grow III-V semiconductor crystals. Undoped crystals with very high quality, suitable for optical application, are not produced together with material for electronic application. The reason is necessity to fine tune growth a pull process in order to eliminate most of lattice dislocation from produced crystals. Such production is expensive for semiconductor industry. Therefore optical quality GaP is produced by companies specialized in growth of optical crystals.

Another promising method is VGF (Vertical Gradient Freeze) method which allows control over temperature gradient in crystallization zone. This reduces amount of lattice dislocations and improves optical transmission of the crystal. Market for optical quality GaP crystals is still small and investment into development of a VGF technology quite large. Authors do not know any company with successful production using this method. On the other hand there are companies producing quality GaAs crystals by VGF method.

\section{Production of GaP optical elements}

SPDT is most versatile method for processing infrared materials like $\mathrm{ZnS}$, $\mathrm{ZnSe}$ or GaAs, but producing optical surfaces for VIS range on GaP is problematic. The TOPEC research centre produces optical elements from $\mathrm{GaP}$ with planar and spherical surfaces by optimized grinding-lapping-polishing cycle. Most problematic behavior of $\mathrm{GaP}$ is production of phosphine $\mathrm{PH}_{3}$ whenever phosphorus atoms on the surface can react with water. $\mathrm{PH}_{3}$ is very dangerous gas [11] and all manufacturing steps must be handled with caution and proper equipment. For a bulk material and surfaces of optical elements it is not a problem, because only a very small portion of phosphorus atoms is exposed. A large surface area is constantly opened during grinding and polishing processes and fresh phosphorus atoms are exposed. Production of $\mathrm{PH}_{3}$ becomes significant. There are two ways to inhibit production of $\mathrm{PH}_{3}$. First is eliminating water from production process - i.e. using alcohols or oils as replacement of the water in grinding and polishing slurries. Use of oils or alcohols creates serious problem with waste separation and disposal, which increases running costs. Second solution, chosen by the TOPTEC centre, is use of additives in water based slurries, which causes immediate oxidation of $\mathrm{PH}_{3}$ dissolved in the slurry. By-product of this process is small amount of phosphorus acid.

Grinding and polishing of spherical surfaces on GaP proves to be problematic due to the anisotropy of the crystal and etching effects of additives that suppress production of $\mathrm{PH}_{3}$. It causes unequal removal rates at different angles and different positions on the surface of produced element.

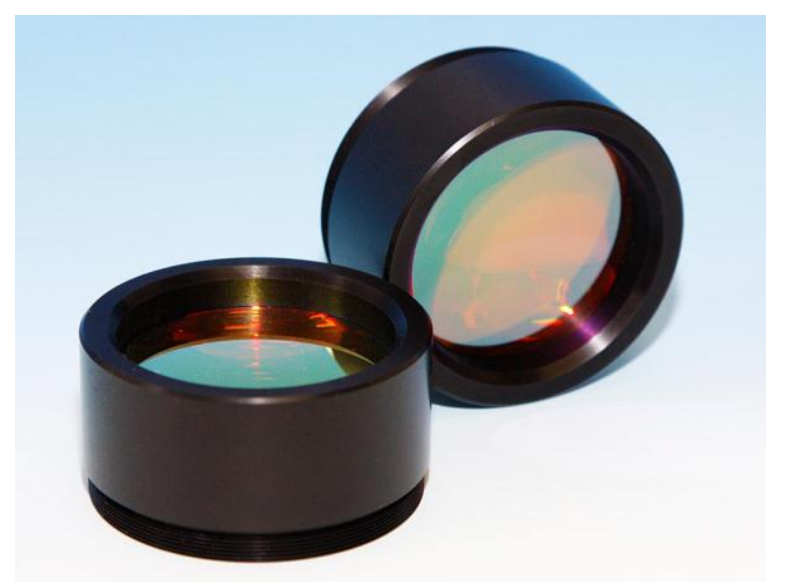

Fig. 5. MWIR objectives with $\mathrm{GaP}$ elements and $47 \mathrm{~mm}$ aperture produced for GfE - Gesellschaft fuer Fertigungstechnik und Entwicklung e.V., Schmalkalden (Germany). 


\section{Application example}

Many of the possible applications of GaP material in as an optical element are focused on mixed VIS-IR systems. It could be for example an optical element of thermal imager that needs common optical path for visible and infrared detectors.

Let's have a simpler problem - creating single lens for focusing or collimating laser beam at $1064 \mathrm{~nm}$ with smallest possible spot for given focal length. This example was chosen to emphasize importance of very high refractive of this material. As the application is monochromatic a low dispersion materials like $\mathrm{CaF}_{2}$ do not offer any advantage. Table 2 shows parameters of lenses with $\mathrm{EFL}=60 \mathrm{~mm}, \mathrm{~F} / 3$ produced from different materials. Dimensions of the lens and meaning of parameters in the table 2 is closely explained in drawing in figure 6. Shapes of these lenses were calculated in ZEMAX software. It clearly shows that $\mathrm{GaP}$ can produce more than six-times smaller focused spot than lens made from $\mathrm{CaF}_{2}$.

Example of another lenses produced from $\mathrm{GaP}$ is displayed in figure 5. These lenses were produced as objective for MWIR line-scan camera measuring temperature of a punching tool.

High dispersion of refractive index can be exploited in systems where a compact refractive dispersion element is required.

Table 2. Comparison of spot sizes and geometric parameters of lenses with $\mathrm{EFL}=60 \mathrm{~mm}$ and $\mathrm{f} / 3$ at $\lambda=1064 \mathrm{~nm}$ made from various optical material

\begin{tabular}{|c|c|c|c|c|c|c|}
\hline & $\mathrm{GaP}$ & $\mathrm{ZnSe}$ & $\mathrm{ZnS}$ & Saphire & $\mathrm{CaF}_{2}$ & $\mathrm{BK} 7$ \\
\hline $\begin{array}{c}\text { Spot } \\
\text { radii } \\
(\mathrm{um})\end{array}$ & 9.5 & 13.7 & 15.9 & 29.7 & 61.3 & 49.3 \\
\hline $\begin{array}{c}\mathrm{R}_{1} \\
(\mathrm{~mm})\end{array}$ & 58.47 & 54.73 & 52.85 & 44.1 & 33.93 & 36.86 \\
\hline $\begin{array}{c}\mathrm{R}_{2} \\
(\mathrm{~mm})\end{array}$ & 99.53 & 129.9 & 151.7 & 890.9 & -129.5 & -212.4 \\
\hline
\end{tabular}

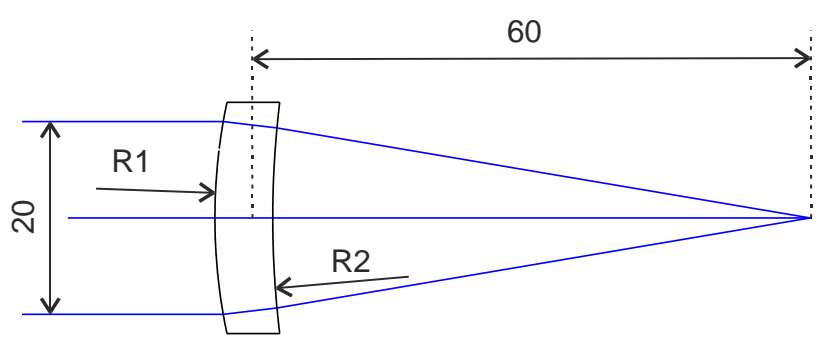

Fig. 6. Dimension of laser focusing lens shown as an example of $\mathrm{GaP}$ application.

\section{Conclusion}

$\mathrm{GaP}$ is a member of family of optical materials usable from VIS do $10 \mu \mathrm{m}$ spectral range. As the family does not have many members compared to VIS/NIR and MWIR/LWIR families, specific optical properties gives optical designer another free parameters to solve optical problems. Important characteristic of $\mathrm{GaP}$ is its mechanical toughness and chemical resistivity compared to other materials in its family.

It was shown that high refractive index in visible range offered by this material can be useful in reducing geometrical aberration.

Material releases dangerous substances during mechanical processing and its anisotropy leads to irregular removal rates in polishing. TOPTEC research center successfully produces spherical and planar optical elements from $\mathrm{GaP}$ and currently works on improvement of manufacturing process.

This work was supported by the European Regional Development Fund and the Ministry of Education, Youth and Sports of the Czech Republic in the Project No. CZ.1.05/2.1.00/03.0079: Research Center for Special Optics and Optoelectronic Systems (TOPTEC) and Project EUREKA E!3869 Infrasens OE10003.

\section{References}

1. F. Ye, ECE226 Optoel. Dev., (2012)

2. M. M. El-Nahass, H. S. Metwally, H. E. A. ElSayed, F. Abd El-salam, H. A. Hassan, Eur. Phys. J. App. Phys., 43, 31 (2008),

3. E. D. Palik, Handbook of Optical Constants, Vol.1, (1985)

4. E. D. Palik, Handbook of Optical Constants, Vol.2, (1991)

5. E. D. Palik, Handbook of Optical Constants, Vol.3, (1998)

6. Marvin J. WEBER, Handbook of optical materials, (2003)

7. C. P. Chen, JPL Publication, 84-81, (1984)

8. TYDEX Optics, CVD-ZnSe, (2012)

9. S. W. Freiman, JOHN J. Mecholsky Jr., ROY W. Rice, J. C. Wurst, J. of the Amer. Cer. Soc., 58, 406, (1975)

10. W. Vidrine, Mechanical properties of transmissive optical materials, (2012)

11. Ch. Salocks, K. B. Kaley, PHOSPHINE (2012) 